John Carroll University

Carroll Collected

2018 Faculty Bibliography

Faculty Bibliographies Community Homepage

$4-2018$

\title{
Thorium and Molten Salt Reactors: Essential Questions for Classroom Discussions
}

\author{
Gregory A. DiLisi \\ John Carroll University, gdilisi@jcu.edu \\ Allison Hirsch* \\ John Carroll University \\ Meredith Murray* \\ John Carroll University \\ Richard Rarick \\ Cleveland State University
}

Follow this and additional works at: https://collected.jcu.edu/fac_bib_2018

Part of the Education Commons, and the Physics Commons

\section{Recommended Citation}

DiLisi, Gregory A.; Hirsch*, Allison; Murray*, Meredith; and Rarick, Richard, "Thorium and Molten Salt Reactors: Essential Questions for Classroom Discussions" (2018). 2018 Faculty Bibliography. 10.

https://collected.jcu.edu/fac_bib_2018/10 


\title{
Thorium and Molten Salt Reactors: Essential Questions for Classroom Discussions
}

\author{
Gregory A. DiLisi, Allison Hirsch, and Meredith Murray, John Carroll University, University Hts., OH \\ Richard Rarick, Cleveland State University, Cleveland, $\mathrm{OH}$
}

A little-known type of nuclear reactor called the "molten salt reactor" (MSR), in which nuclear fuel is dissolved in a liquid carrier salt, was proposed in the 1940s and developed at the Oak Ridge National Laboratory in the 1960s. Recently, the MSR has generated renewed interest as a remedy for the drawbacks associated with conventional uranium-fueled light-water reactors (LWRs) in use today. Particular attention has been given to the "thorium molten salt reactor" (TMSR), an MSR engineered specifically to use thorium as its fuel. The purpose of this article is to encourage the TPT community to incorporate discussions of MSRs and the thorium fuel cycle into courses such as "Physics and Society" or "Frontiers of Physics." With this in mind, we piloted a pedagogical approach with 27 teachers in which we described the underlying physics of the TMSR and posed five essential questions for classroom discussions. We assumed teachers had some preexisting knowledge of nuclear reactions, but such prior knowledge was not necessary for inclusion in the classroom discussions. Overall, our material was perceived as a real-world example of physics, fit into a standards-based curriculum, and filled a need in the teaching community for providing unbiased references of alternative energy technologies.

\section{The thorium-uranium breeding cycle}

The MSR was the subject of a detailed design study, called the Molten Salt Reactor Experiment, conducted at Oak Ridge National Laboratory in the 1960s. Overall, the study demonstrated that the MSR concept was viable; in fact, a prototype MSR operated safely from 1965 to 1969 . However, because of national funding priorities, further development of the MSR was scrapped in 1976 in favor of conventional uranium-fueled LWRs, thus effectively ending research of the MSR for the next 30 years. Over the last decade, scientists have renewed their interest in MSRs as a worthwhile alternative to traditional reactor concepts. Much of the excitement centers on the notion of TMSRs as "breeders"-reactors in which more fissile fuel is generated than is consumed by the reactor. Breeding occurs to some extent in all reactors, but the goal of designing a "breeder reactor" is to produce at least as much fissile material as is consumed by fission in the reactor. To understand the design of a TMSR, one must first examine the physics of the thorium-uranium breeding cycle.

In nature, virtually all thorium is found as the isotope Th-232, which is a "fertile" material-meaning that although it is not fissionable itself, it can be converted into fissile material by suitable neutron absorption and thus be used as fuel in nuclear reactors. Once neutron absorption occurs, the resulting ${ }_{90}^{233} \mathrm{Th}$ nucleus emits a beta particle and decays into protactinium-233 $\left({ }_{91}^{233} \mathrm{~Pa}\right)$, which in turn emits another beta particle and decays into the fissile isotope U-233 $\left({ }_{92}^{233} \mathrm{U}\right)$. The U-233 nucleus is then struck by another neutron that splits the nucleus into lighter fission products, releases a large amount of energy, and produces more neutrons to perpetuate the cycle. In short, when a Th-232 nucleus absorbs a neutron, it eventually metamorphoses (i.e., "breeds") into a U-233 nucleus that is fissionable. The cycle is represented symbolically as ${ }^{1}$ :

$$
\begin{gathered}
{ }_{90}^{232} \mathrm{Th}+n \longrightarrow{ }_{90}^{233} \mathrm{Th}+\gamma \underset{\beta^{-}}{{ }_{22 \mathrm{~min}}}{ }_{91}^{233} \mathrm{~Pa} \underset{{ }_{91}}{\longrightarrow}{ }_{27 \text { day }}{ }_{92}^{233} \mathrm{U}+n \\
\text { Fission Products }+2.3 n+198 \mathrm{MeV} .
\end{gathered}
$$

Notice that using Th-232 as the basis of a breeder reactor is possible because 2.3 neutrons (on average) are released when the U-233 nucleus fissions. These neutrons are considered "fast" neutrons that are not likely to cause fission or be absorbed. However, if these neutrons can be slowed by a neutron moderator, they will interact with the various nuclei and a chain reaction will ensue. ${ }^{2,3,4}$ Neutrons that have been slowed are referred to as "thermal neutrons" because they have essentially only the energy they would have from their temperature. ${ }^{5}$

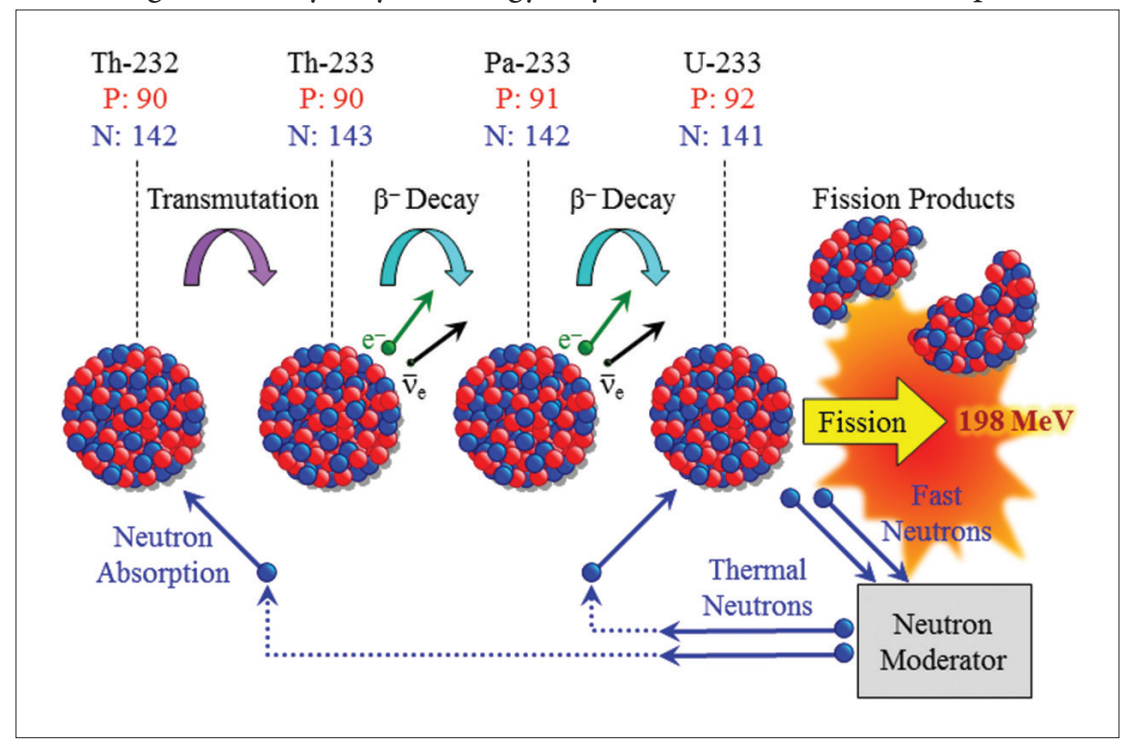

Fig. 1. The thorium-uranium breeding cycle. The Th-232 absorbs a neutron and transmutes to Th-233. After two beta decays, the resulting U-233 can undergo fission and release energy as well as an average of 2.3 "fast" neutrons. These neutrons are statistically unlikely to cause additional fission, so a moderator absorbs most of their kinetic energy and renders them "thermal." 
The take-home message is that neutrons must be "thermal" to produce fission in a nuclear reactor and that everything hinges on the statistics and complex physics of the various nuclei involved. The breeding cycle is depicted in Fig. 1.

\section{Thorium molten salt reactors}

In an MSR, solid nuclear fuel is dissolved in a hightemperature, molten carrier salt (such as sodium fluoride, lithium fluoride, or uranium tetrafluoride), which circulates between the reactor core and an external heat exchanger. These carrier salts are crystalline at room temperature and become clear liquids when heated. Within the core, the nuclear fuel undergoes the nuclear fission process and raises the temperature of the salt that then carries the heat to the heat exchanger. Specifically, the TMSR is designed so that an initial mass of fissile U-233 is supplied to the inner core of the reactor to start the fission chain reaction. Once started, the 2.3 thermal neutrons created during each fission process will maintain the reaction: one neutron colliding with a U-233 nucleus, splitting it into two smaller nuclei, and releasing energy. A second neutron then collides with another fertile Th-232 nucleus that absorbs the neutron and metamorphoses into a fissile U-233 nucleus to continue the breeding cycle. Statistically, this leaves 0.3 neutrons to escape or leak to other parts of the reactor. At this point in its operation, the reactor must only be supplied with thorium. The U-233 is extracted in a chemical process and returned to the core for fuel. Meanwhile, the fuel salt is pumped to a heat exchanger where the

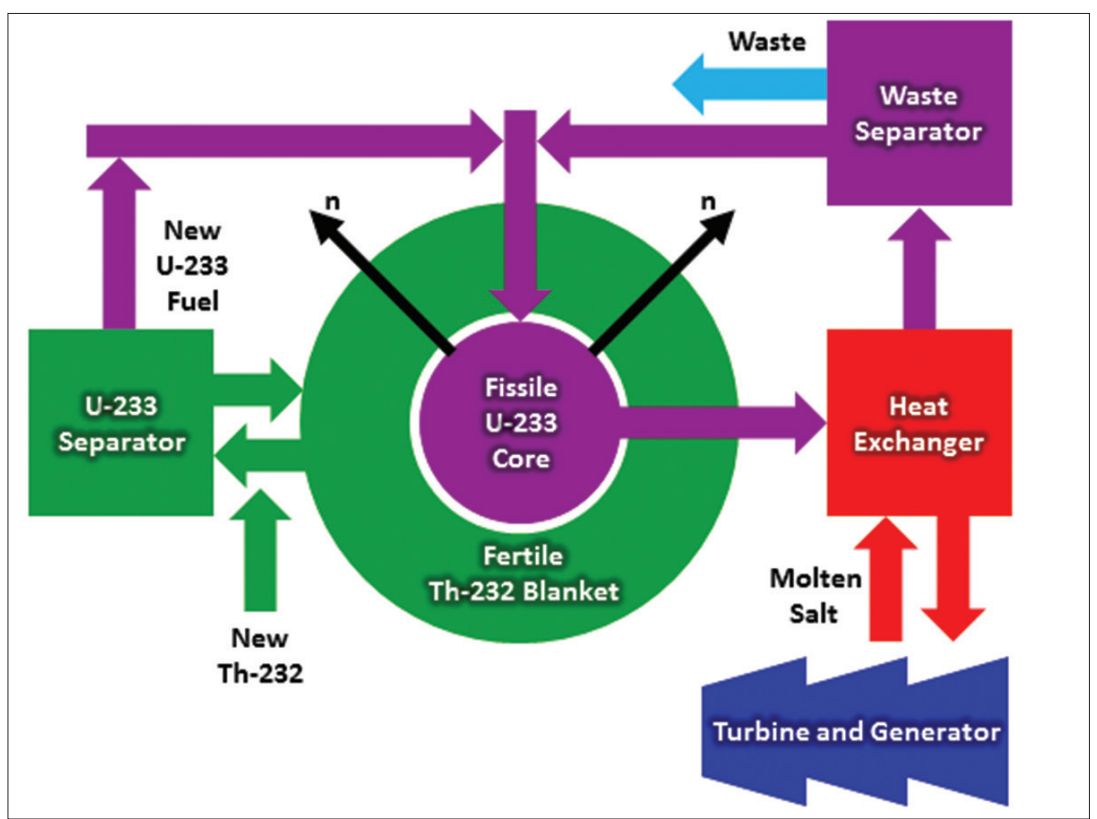

Fig. 2. Schematic of a two-fluid thorium molten salt reactor. The arrows in the schematic depict the circulating molten carrier salt that circulates in two separate loops. In the first circuit (purple), nuclear fuel extracted from thorium ore and dissolved into the molten carrier salt passes through the heat exchanger. A separate circuit (red), carrying no nuclear fuels, transfers heat to spin the gas turbine and generator. Excess neutrons are absorbed by the thorium blanket (green), which in turn metamorphoses into U-233 that is removed by the separator. Fission products are removed chemically by the waste separator. heat can be used to drive a gas turbine. TMSRs can be engineered using a two-fluid design, in which the fertile material is dissolved in one circuit of molten salt while a separate, nonradioactive circuit is used to transfer heat. The single- and double-fluid variations have trade-offs in terms of complexity, performance, and proliferation risk, but, again, the focus of this article is the reactor's basic design, so we collectively label these variations as "TMSRs." A schematic representation of a typical two-fluid TMSR is shown in Fig. 2.

\section{The Generation IV Roadmap and essential questions for classroom discussions}

In 2001, 13 of the world's governments, representing countries that produce nuclear power, met in Washington, DC. Their aim was to sign a charter forming a cooperative, the Generation IV International Forum (GIF), self-described as "a partnership for sustainable nuclear energy systems." 6 The GIF established the Generation IV Roadmap-several broad criteria that guide the next generation of power plant designs: (i) safety, (ii) waste management, (iii) economics, (iv) the prevention of arms proliferation, and (v) fuel supply. We used these five criteria to form essential questions for classroom discussion in order to help teachers and students evaluate the design of TMSRs vs. LWRs.

1. Which is safer? During routine operations, all reactors emit radioactive materials into the environment. The safety of a reactor is judged by the likelihood of these materials to have harmful consequences on humans or the environment. Additionally, experts evaluate safety based on how quickly a reactor can be shut down and effectively maintained.

Critics: Critics note that hazardous metals and mill tailings (i.e., radioactive by-products) are unearthed whether thorium or uranium is mined and that the health risks associated with thorium are equal to or much greater than those associated with uranium. Additionally, once mined, the use of thorium increases health risks primarily because thorium itself cannot be used to start a nuclear reaction so a fissile material like U-233 is needed. The nuclear reactions that consume U-233 also produce small amounts of U-232 that has a decay sequence which includes hard gamma-ray emitting radioisotopes. This radiation necessitates remote handling and makes worker protection more difficult and expensive.

Advocates: The TMSR is intrinsically stable with respect to meltdown of the reactor core. In an LWR, the core's reactivity is positively correlated to its temperature; that is to say, as the core heats up, fission increases and the reactor can become unstable. Conversely, 
in a TMSR, the core's reactivity is negatively correlated to its temperature, so as the temperature of the core increases, its reactivity decreases and fission stops by default. Essentially, physics itself is the TMSR's fail-safe. Finally, the TMSR design incorporates a passive safetycontrol feature: freeze plugs in the molten salt plumbing are kept cool by fans. If, for any reason, the plugs melt, the molten salt is dumped into in-ground sump tanks where the heat in the molten salt is dissipated and the reaction stops.

2. How do we dispose of waste? In terms of efficiency, advocates and critics agree that the high temperature operation of the TMSR makes it an efficient system. For instance, a TMSR is capable of a thermal efficiency in the $42-50 \%$ range as compared to the average $33 \%$ efficiency of a conventional plant. ${ }^{7-9}$ As a result, the overall fuel utilization associated with TMSRs appears to be significantly better than that of standard LWRs. Therefore, our essential question focuses instead on waste.

if Critics: Critics contend that while the mix of fission products from thorium refinement is different than with uranium, a similarly dangerous batch of fission products will be created. Therefore, a geologic repository, of the order of tens to hundreds of thousands of years, will still be required regardless of the breeding cycle.

Advocates: Advocates assert that since most of the products of the thorium-uranium breeding cycle have short half-lives compared to longer-lived actinide wastes (the typical wastes associated with LWRs), the containment period in a geologic repository will instead be greatly reduced from tens of thousands of years to 300-500 years. Also, an important feature of a TMSR is that virtually all of the thorium fuel eventually is converted to the fissile isotope $\mathrm{U}-233$ to produce nuclear energy. Conversely, in an LWR, only $4 \%$ of the uranium consists of the fissile isotope U-235, which can undergo fission, while the remaining $96 \%$ consists of U-238 (contaminated with the radioactive products of fission). Eventually these fission products "poison" the fuel by absorbing neutrons so that the uranium fuel rods must be replaced about every two years. As a result, the TMSR design can reduce uranium enrichment requirements by a factor of three to four. ${ }^{3}$

3. What is the cost of implementation? Are the start-up expenses associated with a TMSR worth the initial higher investment in the hopes of producing cheaper TMSRs sometime in the future?

㯪 Critics: TMSRs have two cost disadvantages. First, much of the actual engineering of a TMSR remains untested. Although research in MSRs was conducted at the ORNL in the 1960s, resulting in the concept for a molten salt breeder reactor based on the thorium fuel cycle, no other MSRs were ever operated in the United States and no MSR ever used thorium fuel. $3,10,11$ Thus, many engineering details remain to be investigated for full- scale implementation. The second, more incalculable cost is that TMSRs will require regulatory changes to accommodate their new design, and to ensure the safety of both workers and the environment. The rules governing nuclear reactors were written for older generation reactors and are simply not applicable to new designs. The gap in development and overhaul of regulations will lead to technical complications and an upsurge in cost.

Advocates: The primary cost advantage of the TMSR is that it incurs low capital costs. With any reactor, the high cost of uranium enrichment, plutonium separation, fuel rod production, and reprocessing always exists; but TMSRs are cheaper to build because they are smaller than LWRs and have less expensive control and emergency systems. Furthermore, TMSRs do not require a containment dome since they cannot melt down. In fact, since the word "molten" only describes the heated carrier salt, advocates of MSRs want to remove the word "molten" from the reactor's moniker since it unintentionally connotes the idea of a "meltdown" to the general public. TMSRs have no need for fuel rod manufacturing, with some designs using problematic transuranic elements from existing LWRs as their fuel. ${ }^{12}$ Finally, a TMSR is comparatively easy and fast to turn on and off. For instance, prototype reactors were "turned off for the weekend" to save costs. The only real start-up energy required to reactivate the TMSR is that needed to melt the salt and run the pumps to circulate the molten salt through its plumbing. LWRs have no comparable means of quickly "shutting off."

\section{Can reactor fuels be used to make nuclear} weapons? Evaluating the design of a nuclear reactor based on its potential for arms proliferation is difficult because terrorists will find all the Gen IV designs a tempting source of weapons-grade materials. Also, the question of "state-sponsored" proliferation must be addressed. Would throwing out inspectors from the International Atomic Energy Agency (IAEA) and building a bomb be easier for a state with an infrastructure based on TMSRs than for one based on LWRs? Therefore, the essential question boils down to whether or not weapons production is easier to accomplish using the fuels of TMSRs than with those of LWRs. Overall, the proliferation risks appear to be equal. ${ }^{3}$

i Critics: Critics argue that since a fissile material (the $\mathrm{U}-233$ ) is needed to start the nuclear reaction, bombmaking material will inevitably be available at some place in the reactor and thus vulnerable to theft. ${ }^{13}$ Even though Feiveson et al. noted that "there are no indications that U-233 is used in operational nuclear weapons today," the Times of India reported that one of India's test explosions was a U-233 warhead. ${ }^{4,14}$ Although the latter source is not peer reviewed and should be viewed with skepticism, it suggests that the current situation, at least in the open literature, is murky. Perhaps even more attractive to terrorists, the U-233 not only has a much 
smaller critical mass than that of U-235, but it does not suffer the premature initiation issue that $\mathrm{Pu}-239$ does, so it could be incorporated into a gun-type design-a huge simplification over $\mathrm{Pu}-239 .{ }^{4}$ Critics also point out that TMSRs result in the inevitable production of $\mathrm{Pu}$ 239 , so the proliferation problem remains since either bomb-usable U-233 or $\mathrm{Pu}-239$ exists.

Advocates: Advocates claim that weapons-grade fissionable U-233 is extremely difficult to retrieve safely and is easily detected because of the production of U-232 in the reactor. Again, the production of U-232 emits hard gamma-ray radiation that is deadly to the handler and easily detected. Advocates also point to a variation of the TMSR design that involves the use of "denatured fuel," elemental and isotopic fuel compositions that are considered non-weapon-usable at all times. For example, one method of preventing the buildup of U-233 in thorium fueled reactors is to add natural or depleted uranium to the fuel. ${ }^{3}$

5. Is enough fuel available? Critics and advocates have come to some consensus on at least one question regarding TMSRs. Both agree that thorium is a promising nuclear fuel since it is abundant and readily available from a number of sources. (See the online appendix for details). ${ }^{15}$

\section{Teacher reactions and classroom discus- sions}

We gave the above information to 27 secondary science teachers and asked them to reflect on how they might use it to plan and implement instruction. First, we report on the teachers' general reception as well as their perceptions of the extent and ease with which the material could be used. All 27 respondents welcomed the opportunity to incorporate current events into their classrooms, especially those involving alternative energy sources. According to teachers, this was an effective way to contextualize physics using a real-world situation that is relevant to students' backgrounds. For example, one teacher commented, "My students are so bombarded with energy-related information from the news and social media that I welcomed the chance to bring an actual realworld debate into my classroom." Additionally, teachers commented that the topic easily fit within the evolving standards dedicated to energy and technology. Therefore, teachers felt they could successfully incorporate this material into a tightly controlled curriculum. All teachers commented that the material begins to fill an important need in the teaching community, that is, providing an unbiased analysis of alternative energy sources.

Regarding the underlying physics of MSRs, reactions were mixed. Seventeen respondents commented that although they understood the overall content, students would need to know more about isotopes, beta decay, and the chains of radioactive decays to better grasp the arguments of the thorium-uranium breeding cycle. One teacher noted, "The specifics of the breeding cycle are beyond the scope of my introductory class so I won't use the background material as much as I will use the essential questions."

All respondents acknowledged the relevance of the essential questions, but had mixed opinions on the effectiveness of each question. First, all respondents appreciated the framework with which to evaluate nuclear reactors as set forth by the Gen IV Roadmap. Prior to seeing the roadmap, respondents had no organized means of comparing reactor designs or alternative technologies. As one teacher remarked:

"I had no frame of reference for comparing energy technologies and actually had never thought of organizing a comparison like the one based on the Gen IV Roadmap .... The biggest contribution of your material was simply to organize my thoughts on how I can present a balanced analysis. I will use this roadmap when discussing solar panels, wind turbines, geothermal pumps, biofuels, etc."

Concerns on the effectiveness of the essential questions centered on the teachers not being convinced by the arguments of the advocates or critics. When asked whether they had enough information to discuss the essential questions, 18 teachers identified question 1 (safety) as needing the most additional information while none of the teachers were interested in gathering additional information on question 5 (supply). Interestingly, students found question 4 (proliferation of weapons) to be the most captivating. When asked how this information might be used in the classroom, eight teachers noted that students wanted a classroom discussion on how terrorists can exploit energy technologies. One teacher described, "My students started a discussion on nuclear proliferation that soon turned into one on gasoline attacks and biological weapons (anthrax). I guess the threat of terrorism is never far from their minds."

Finally, teachers overwhelmingly encouraged the TPT community to contribute additional papers on related subjects. Several respondents mentioned that creating a repertoire of papers, or a dedicated issue, describing the physics of cutting-edge alternative energy sources and a compilation of their associated "pros vs. cons" would be a great contribution of TPT to teachers. One teacher remarked: "There is so much information out there, I don't know what is important and what to believe. However, if I read something in $T P T$, at least I know it has been vetted."

\section{References}

1. S. Shengyi, "Roadmap design for thorium-uranium breeding recycle in PWR," IAEA-CN-164-5S09, International Conference on Opportunities and Challenges for Water Cooled Reactors in the 21st Century (Vienna, Austria, Oct. 27-30, 2009).

2. J. Kang and F. N. von Hippel, "U-232 and the proliferation resistance of U-233 in spent fuel," Sci. Global Secur. 9 (1), 1-31 (2001).

3. A. Ahmad, E. B. McClamrock, and A. Glaser, "Neutronics 
calculations for denatured molten salt reactors: Assessing resource requirements and proliferation-risk attributes," Ann. Nucl. Energy 75, 261-267 (2015).

4. H. Feiveson, A. Glaser, Z. Mian, and F. von Hippel, Unmaking the Bomb (MIT Press, Cambridge, MA, 2014).

5. R. Muller, Physics for Future Presidents (W. W. Norton and Company, New York, 2008).

6. The Generation IV International Forum, "Charter of the Generation IV International Forum,” http://www.gen-4.org/PDFs/ GIFcharter.pdf, accessed on Sept. 17, 2016.

7. A. Juhasz, R. Rarick, and R. Rangarajan, "High Efficiency Nuclear Power Plants Using Liquid Fluoride Thorium Reactor Technology," 7th International Energy Conversion Engineering Conference, Denver, CO (August 2-5, 2009).

8. P. DiPietro, Improving Efficiency of Coal-Fired Power Plants for Near Term $\mathrm{CO}_{2}$ Reductions (National Energy Technology Laboratory, United States Department of Energy, Washington, DC, Nov. 2009).

9. J. R. Engel et al., Conceptual Design Characteristics of a Denatured Molten-Salt Reactor with Once-Through Fueling, ORNL/ TM-7207 (Oak Ridge National Laboratory, Oak Ridge, TN, 1980).

10. P. N. Haubenreich and J. R. Engel, "Experience with moltensalt reactor experiment," Nucl. Appl. Technol. 9, 118-139 (1969).

11. P. R. Kasten, E. S. Bettis, H. F. Bauman, and W. L. Carter, Summary of Molten-Salt Breeder Reactor Design Studies, ORNLTM-A467 (Oak Ridge National Laboratory, Oak Ridge, TN, 1966).

12. N. Endicott, Report for the All Party Parliamentary Group on Thorium Energy - Thorium-Fuelled Molten Salt Reactors (The Weinberg Foundation, UK, June 2013).

13. T. Ehresman (ed.), "Molten Salt Reactor (MSR)," (Fact Sheet), 08-GA50044-17-R1 R6-11 (Idaho National Laboratory), http:// www4vip.inl.gov/research/molten-salt-reactor/, accessed on Nov. 29, 2016.
14. R Pandit, "Forces gung-ho on N-arsenal: Navy chief confident despite scientist calling pokhran 'fizzle," http://epaper.timesofindia.com/Repository/ml.asp?Ref=VE9JTS8yMDA5LzA4LzI 4I0Fy MDE1MDA, accessed on Nov. 29, 2016.

15. Readers can view the appendix at TPT Online, http://dx.doi. org/10.1119/1.5028245, under the Supplemental tab.

Gregory A. DiLisi received his BS from Cornell University in applied and engineering physics and his MS and PhD from Case Western Reserve University in experimental physics. He is currently an associate professor at John Carroll University, where he teaches physics, science methods, and instructional technology courses. As an experimental physicist, he specializes in liquid crystals, with his recent research focusing on stabilizing liquid bridges that shift from micro- to hyper-gravity environments. In the area of science education, his research has focused on problem-solving and team-building in engineering and the sciences. gdilisi@jcu.edu

Allison Hirsch studied international studies and French at Case Western Reserve University and obtained a master's degree in history from the University of Chicago before earning her Master of Education degree from John Carroll University. Currently, she is a high school social studies teacher in Northeast Ohio.

Meredith Murray attended the University of Arizona and obtained a B.S. in Science Education before earning her Masters of Secondary Education at John Carroll University. She is currently teaching seventh and eighth grade science at Joseph and Florence Mandel Jewish Day School in Beachwood, $\mathrm{OH}$.

Richard A. Rarick received his BS from Cleveland State University in electrical engineering and his MS from Cleveland State University in applied mathematics. After working in the private sector as an engineer in the fields of digital signal processing and control theory, he now is a member of the faculty in the Department of Electrical Engineering and Computer Science at Cleveland State University specializing in electronics, control theory, electro-mechanical energy conversion, and embedded systems. 